\title{
Inclusion Mechanism and Heat Stability of the Complex of 4'-Hydroxychalcone and Hydroxypropyl- $\beta$-Cyclodextrin
}

\author{
Yancheng Guo ${ }^{1 *}$, Yuzhen Chen $^{2}$ and Hanjun $\mathrm{Ma}^{1}$ \\ ${ }^{1}$ School of Food Science, ${ }^{2}$ School of Mathematical Sciences, Henan Institute of Science and Technology, Xinxiang 453003, \\ China \\ *For correspondence: Email: yancheng258@163.com
}

\begin{abstract}
Purpose: To study the inclusion mechanism and heat stability of the complex formed between 4'hydroxychalcone and hydroxypropyl- $\beta$-cyclodextrin $(H P-\beta-C D)$

Methods: The inclusion mechanism of the complex of 4'-hydroxychalcone and HP- $\beta-C D$ was investigated by phase solubility method. The physicochemical properties of the complex were evaluated by Fourier transform infrared spectroscopy (FT-IR) and x-ray diffractometry (XRD) while the heat stability of the complex was measured by thermogravimetric/differential scanning calorimetry (TG/DSC). Results: The stability constants of the complexes were higher than those of $\beta-C D$ at all temperatures. For the formation of the complex, Gibbs energy $\left(-16.87 \mathrm{KJ} / \mathrm{mol}\right.$ at $\left.20^{\circ} \mathrm{C}\right)$ was negative, and positive entropy $(31.15 \mathrm{KJ} / \mathrm{mol})$ along with a slightly positive enthalpic change $(163.89 \mathrm{~J} / \mathrm{mol})$ was also found. IR and XRD analysis showed that the physical phase of 4-hydroxylchalcone was changed and completely dispersed in HP- $\beta-C D$ while TG/DSC data indicate that the starting decomposition temperature of 4'hydroxychalcone $\left(200{ }^{\circ} \mathrm{C}\right)$ was significantly enhanced to $397{ }^{\circ} \mathrm{C}$ due to the formation of inclusion complex with $H P-\beta-C D$ in the solid state.

Conclusion: The stability constant of HP- $\beta-C D$ for 4'-hydroxychalcone is higher than that of $\beta-C D$. The inclusion is a spontaneous process, driven by hydrophobic forces. The heat stability of 4'hydroxychalcone is significantly enhanced by complexing with $H P-\beta-C D$.
\end{abstract}

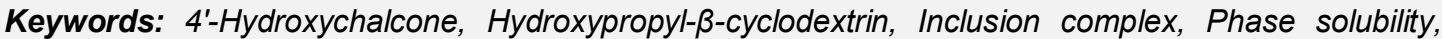
Thermogravimetry, Differential scanning calorimetry

Tropical Journal of Pharmaceutical Research is indexed by Science Citation Index (SciSearch), Scopus, International Pharmaceutical Abstract, Chemical Abstracts, Embase, Index Copernicus, EBSCO, African Index Medicus, JournalSeek, Journal Citation Reports/Science Edition, Directory of Open Access Journals (DOAJ), African Journal Online, Bioline International, Open-J-Gate and Pharmacy Abstracts

\section{INTRODUCTION}

Chalcones, a kind of flavonoid, are polyphenolic compounds that usually exist in plants as secondary metabolites. Several beneficial properties have been attributed to these dietary compounds, including antioxidant, antiinflammatory, and anticarcinogenic, anticancer activities [1-3]. But chalcones are poorly water soluble, which severely restricts its application in medicinal and food formulations.
Cyclodextrins (CDs) are cyclic oligosaccharides consisting of six ( $\alpha$-cyclodextrin), seven ( $\beta$ cyclodextrin), eight ( $\gamma$-cyclodextrin) or more glucopyranose units linked by $\alpha-(1,4)$ bonds, which have been used extensively as additives to increase the solubility of poorly water-soluble organic compounds by the formation of an inclusion complex [4,5]. Hydroxylpropyl- $\beta$ cyclodextrin (HP- $\beta-C D)$, a hydroxyalkyl derivative of cyclodextrin, is an alternative to $\alpha-, \beta$ - and $y$ cyclodextrin, with improved water solubility and may be slightly more toxicologically benign. FDA 
has approved the application of HP- $\beta-C D$ in food, agriculture and the pharmaceutical field [6].<smiles>O=C(/C=C/c1ccccc1)c1ccc(O)cc1</smiles>

Figure 1: Chemical structure of 4'-hydroxychalcone

To the best of our knowledge, there are few reports exploring the complex of HP- $\beta-C D$ and chalcone. In this study, in order to investigate the supramolecular complexation between chalcone and HP- $\beta-C D, 4$ '-hydroxychalcone (Figure 1 ) and two CDs ( $\beta-C D$ and HP- $\beta-C D$ ) were selected for phase-solubility study. The physicochemical properties of the obtained complexes were investigated by IR and XRD. And their heat stabilities were also studied by TG/DSC analysis.

\section{EXPERIMENTAL}

\section{Materials and chemicals}

4'-Hydroxychalcone (> $95 \%$ ) was obtained from Tokyo Chemical Industry Co Ltd (Tokyo, Japan) while (2-hydroxypropyl)- $\beta$-cyclodextrin (average MW 1460) was purchased from Sigma (St Louis, MO). Other chemicals were of analytical grade unless stated otherwise.

\section{Phase solubility studies}

Phase solubility studies were carried out according to the method described by Higuchi and Connors [7]. An excess amount of 4'hydroxychalcone (about $50 \mathrm{mg}$ ) was added to a series of test tubes each containing $5 \mathrm{~mL}$ of $\beta$ $C D$ and HP- $\beta-C D$ solutions at the concentrations ranging from 0 to $10 \mathrm{mM}$, and the mixture was vortexed for $2 \mathrm{~min}$ to disperse the sample. The test tubes were shaken in a rotary water bath (180 rpm) set at $20-40{ }^{\circ} \mathrm{C}$ for $72 \mathrm{~h}$. After that, the mixture was filtered through a $0.45 \mu \mathrm{m}$ membrane filter and appropriately diluted. The concentrations of the dissolved 4'hydroxychalcone in the solution were determined by measuring their absorbance with a TU1810PC UV spectrophotometer (Purkinje, Beijing, China) at $320 \mathrm{~nm}$ comparing them with the corresponding standard curves, respectively. The apparent stability constants (Ks) of the complexes were calculated from phase-solubility diagrams as in Eq 1.

Ks $=$ slope/intercept $(1-$ slope $)$
Preparation of inclusion complex of 4'hydroxychalcone and HP- $\beta-C D$

4'-Hydroxychalcone $(0.224 \mathrm{~g}, 1 \mathrm{mM})$ and HP- $\beta$ CD $(1.460 \mathrm{~g}, 1 \mathrm{mM})$ was mixed in $25 \mathrm{~mL}$ of distilled water, stirred for $72 \mathrm{~h}$ at $40{ }^{\circ} \mathrm{C}$ and filtered through a $0.45 \mu \mathrm{m}$ membrane filter to remove undissolved material. The filtrate was freeze-dried (Alpha 1-2, Christ, Germany) and the resultant powdery material was weighed and collected as the inclusion complex of 4'hydroxychalcone and HP- $\beta-C D$ for the following analysis.

Preparation of physical mixture of 4'hydroxychalcone and HP- $\beta-C D$

4'-Hydroxychalcone $(0.224 \mathrm{~g}, 1 \mathrm{mM})$ and HP- $\beta$ CD $(1.460 \mathrm{~g}, 1 \mathrm{mM})$ was mixed thoroughly in a small beaker at room temperature, respectively. The obtained product was collected as the physical mixture of 4'-hydroxychalcone and HP$\beta-C D$.

\section{Fourier transform infrared spectroscopy (FT- IR)}

FT-IR was conducted using a Tensor 27 FT-IR spectrometer (Bruker, Germany). The spectrum in the mid-IR $\left(400-4000 \mathrm{~cm}^{-1}\right)$ spectral region was collected. The procedure consisted of grinding the sample together with $\mathrm{KBr}$ into a fine powder, placing the powder into the sampling cup, smoothing the powder, and compressing the powder bed into the holder using a compression gauge. The sample was placed in the light path and the spectrum was obtained.

\section{X-ray diffractometry (XRD)}

Monochromatic $\mathrm{Cu} \mathrm{Ka}$ radiation (wavelength = $1.54056 \mathrm{~A}^{\circ}$ ) was produced by a D8 Advance Xray diffractometer (Bruker, Germany). The powdery samples were packed tightly in a rectangular aluminum cell prior to exposure to the X-ray beam. The scanning regions of the diffraction angle, $2 \theta$, were $5-80^{\circ}$ and radiation was detected with a proportional detector.

\section{Thermogravimetric/differential scanning calorimetry measurement (TG/DSC)}

The Q600 TG/DSC system (TA, USA) was adjusted to operate at the following conditions: dynamic atmosphere of nitrogen $(99.999 \%)$ at $100 \mathrm{ml} / \mathrm{min}$ and heating rate of $20^{\circ} \mathrm{C} / \mathrm{min}$ from 20 to $500{ }^{\circ} \mathrm{C}$, with sample mass of about $5 \mathrm{mg}$. 


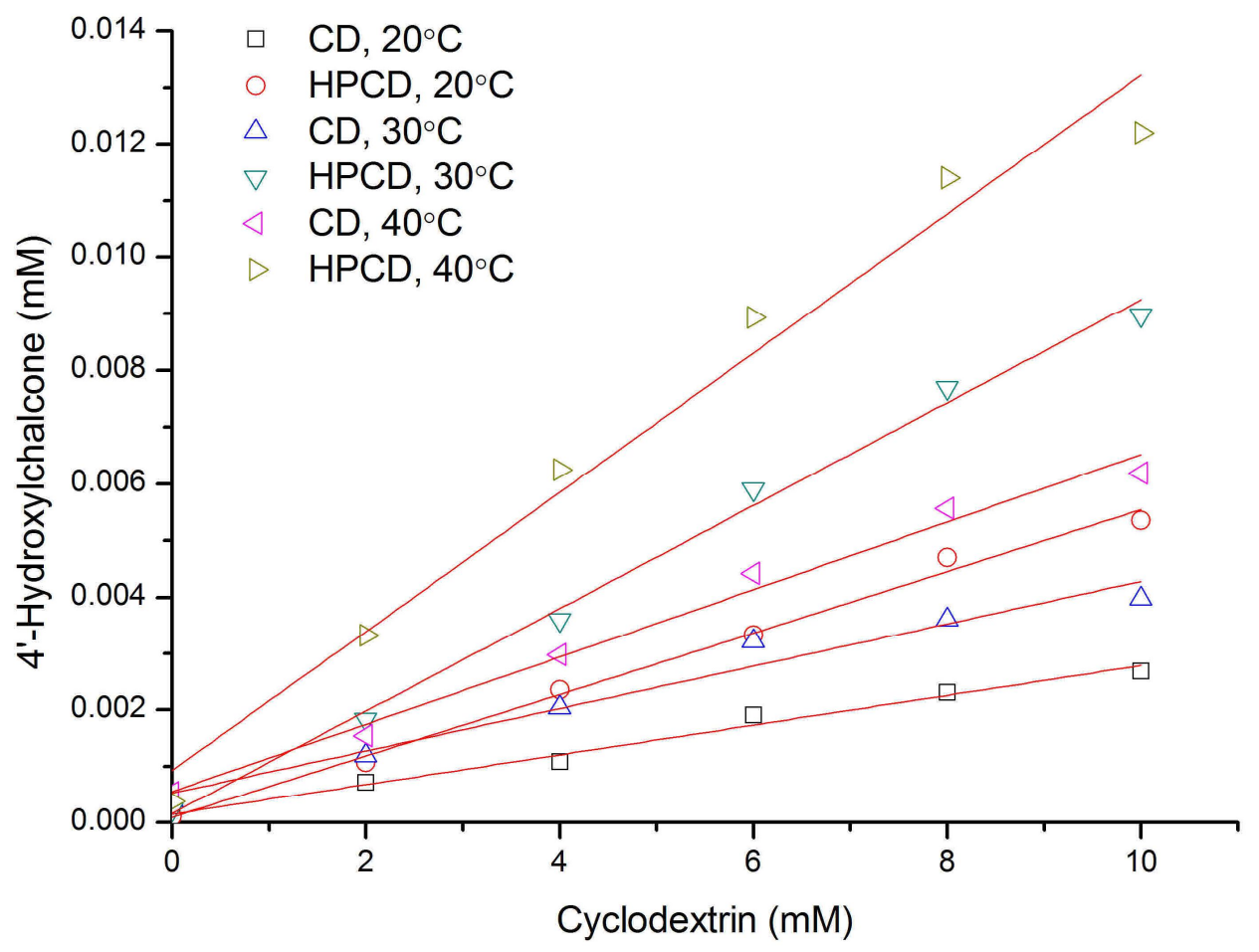

Figure 2: Phase-solubility diagrams of inclusion complexes formed by 4'-hydroxychalcone and cyclodextrins

\section{RESULTS}

\section{Phase solubility result}

The phase-solubility plots of different chalcone$C D$ complexes were showed in Figure 2. It was found the concentration of 4'-hydroxychalcone increased with the increasing $C D$ concentrations. The stability constants (Ks) of the complexes, calculated from the slopes of the linear phasesolubility plots, were summarized in Table 1 . Of the three temperatures, the stability constants were highest for the complexes formed with HP$\beta-C D$, followed by $\beta-C D$.

For the formation of an inclusion complex, there must be a favorable net energetic force that drives the guest into the cyclodextrin cavity [4]. To understand the thermodynamic forces driving the inclusion process between chalcones and CDs, The thermodynamic parameters were calculated from the phase solubility. Based on the Van't Hoff equation (Equation (2)), the changes of enthalpy and entropy were revealed. The Gibbs energy change was also computed from the stability constants using Equation (3) [8].

In $\mathrm{Kc}=-(\Delta \mathrm{H} / \mathrm{RT})+(\Delta \mathrm{S} / \mathrm{R})$

$\Delta G=\Delta H-T \Delta S$

Where $R$ and $T$ are the gas constant and temperature $(K)$, respectively. These thermodynamic parameters for the formation of inclusion complexes between chalcones and CDs were summarized in Table 1.

Table 1: Thermodynamic parameters for the formation of inclusion complexes between 4'-hydroxychalcone and HP- $\beta-C D$

\begin{tabular}{llccccc}
\hline Compound & & $\begin{array}{c}\text { Temperature } \\
\left({ }^{\circ} \mathbf{C}\right)\end{array}$ & $\begin{array}{c}\mathbf{K s} \\
\left(\mathbf{M}^{-1}\right)\end{array}$ & $\begin{array}{c}\mathbf{\Delta G} \\
(\mathbf{K J} / \mathbf{m o l})\end{array}$ & $\begin{array}{c}\Delta \mathbf{H} \\
(\mathbf{K J} / \mathbf{m o l})\end{array}$ & $\begin{array}{c}\Delta \mathbf{S} \\
(\mathbf{J} / \mathbf{m o l})\end{array}$ \\
\hline & \multirow{2}{*}{-CD } & 20 & 479.04 & -14.98 & & \\
4'-Hydroxychalcone & & 30 & 683.10 & -16.56 & 31.07 & 157.18 \\
& & 40 & 1083.84 & -18.13 & & \\
& HP- $\beta-C D$ & 20 & 989.74 & -16.87 & & 163.89 \\
\hline
\end{tabular}




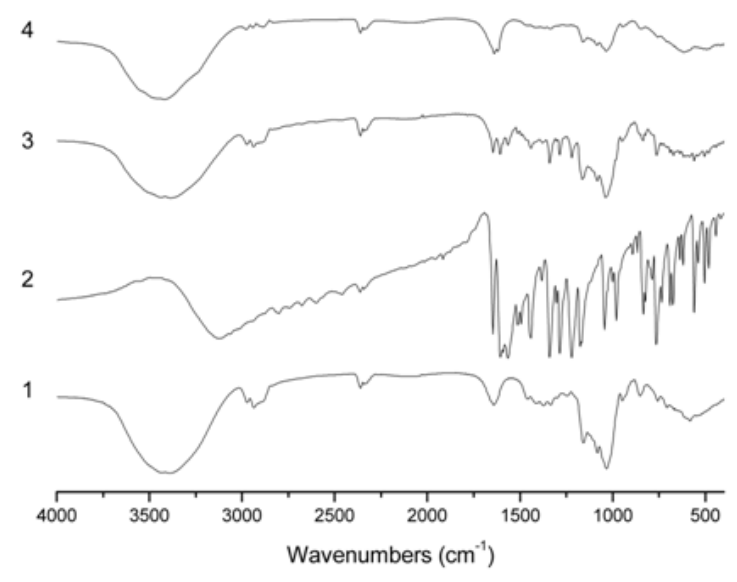

Figure 3: IR spectra of $\mathrm{HP}-\cdot-\mathrm{CD} \quad(1)$, 4hydroxylchalcone (2), their physical mixture (3) and complex (4)

\section{FT-IR spectra}

The infrared spectra of HP- $\beta-C D$, 4'hydroxychalcone, their physical mixture and the complex were shown in Figure 3 . The FT-IR spectrum of HP- $\beta-C D$ showed prominent absorption bands at $3387 \mathrm{~cm}^{-1}$ (for $\mathrm{O}-\mathrm{H}$ stretching vibrations), $2935 \mathrm{~cm}^{-1}$ (for C-H stretching vibrations) and 1158, 1083 and 1033 $\mathrm{cm}^{-1}$ (for $\mathrm{C}-\mathrm{H}, \mathrm{C}-\mathrm{O}$ stretching vibration). The FTIR spectrum of 4-hydroxychalcone and 4'hydroxychalcone consisted of the prominent absorption bands of the hydroxyl group ( about $3122 \mathrm{~cm}^{-1}$ ), the aromatic conjugated carbonyl group (about $1646 \mathrm{~cm}^{-1}$ ) and the aromatic nucleus (about 1566, 1512, 1494, $1442 \mathrm{~cm}^{-1}$ ). The IR spectra of the physical mixture of HP- $\beta$ $C D$ and chalcones displayed the spectral addition effect and were essentially a combination of the spectra of HP- $\beta-C D$ and corresponding chalcone. However, in the spectra of their inclusion complex, several small but characteristic absorption peaks of chalcone between 400 and $1600 \mathrm{~cm}^{-1}$ almost disappeared.

\section{XRD}

The powder x-ray diffraction patterns of HP- $\beta$ $\mathrm{CD}, \quad 4$ '-hydroxychalcone, their mixture and complex were shown in Figure 4. The powder diffraction pattern of 4'-hydroxychalcone displayed sharp crystalline peaks, which is the characteristic of an organ molecule with crystallinity. In contrast, HP- $\beta-C D$ showed two broad peaks lacking crystalline peaks. The XRD pattern of the physical mixture of the powder of 4'-hydroxychalcone and HP- $\beta-C D$ showed essentially a superposition of the patterns of the two compounds, confirming that no inclusion was formed between them and both retained their original physical characteristics.

In contrast, the XRD pattern of the inclusion complex was virtually the same as that of the amorphous HP- $\beta-C D$ and exhibited none of the characteristic peaks of 4'-hydroxychalcone.

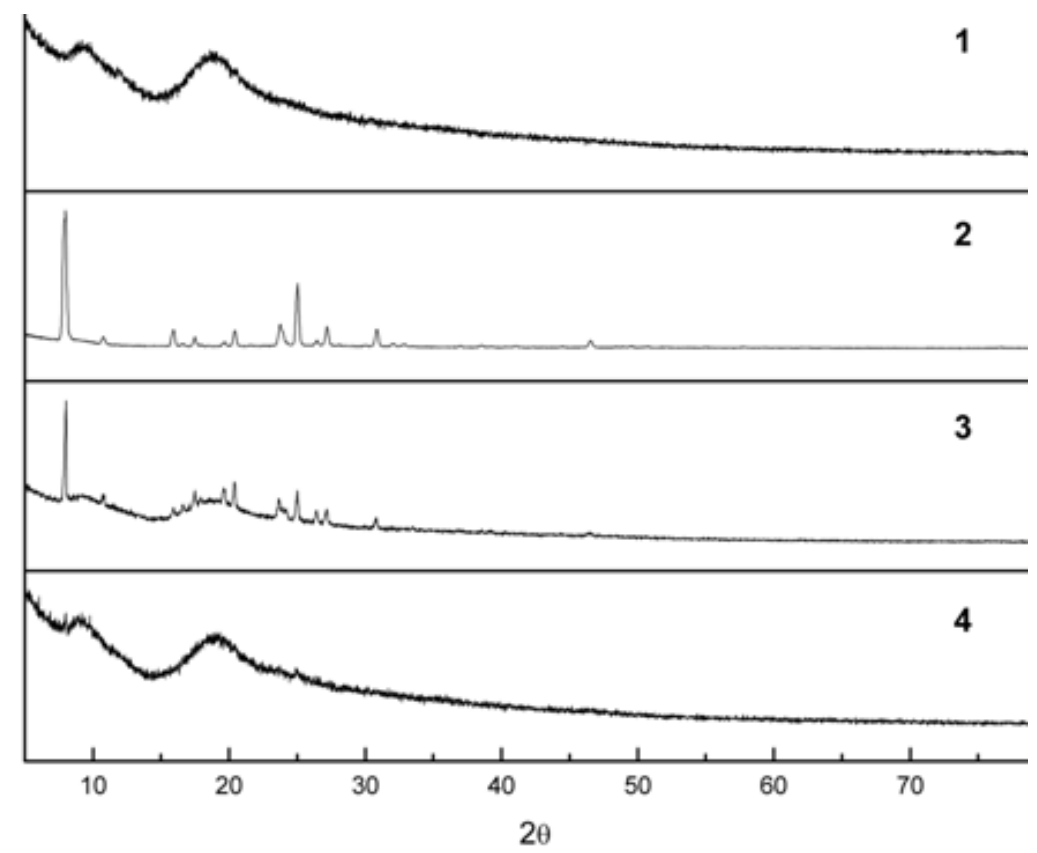

Figure 4: XRD patterns of HP- $\beta-C D(1)$, 4-hydroxylchalcone (2), their physical mixture (3) and complex (4) 


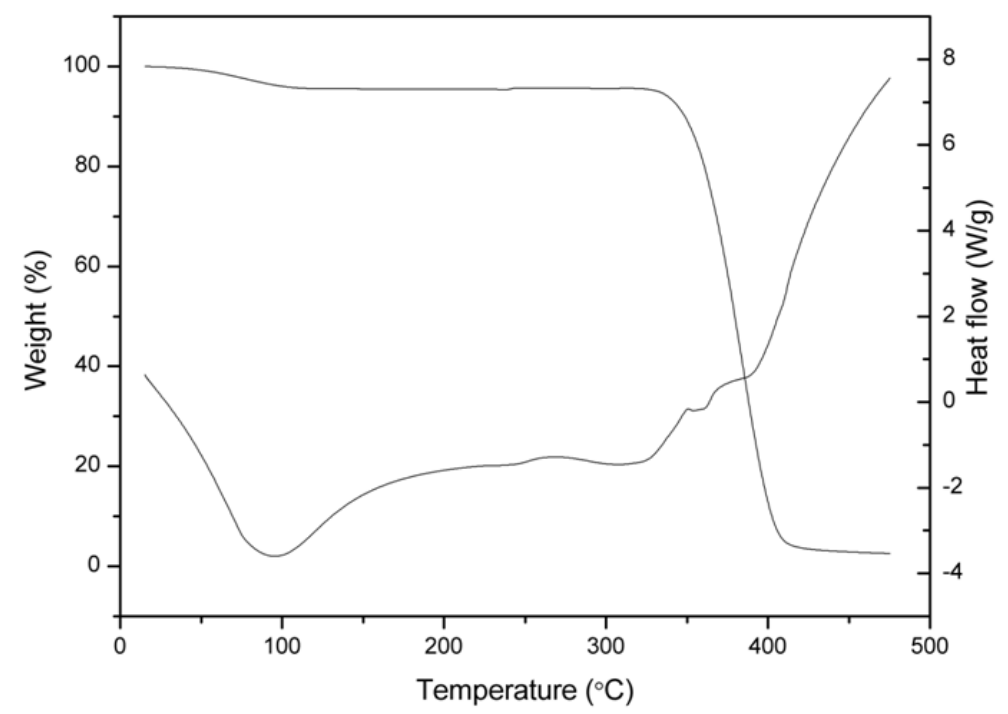

Figure 5: TG/DTA curves of HP- $\beta-C D$
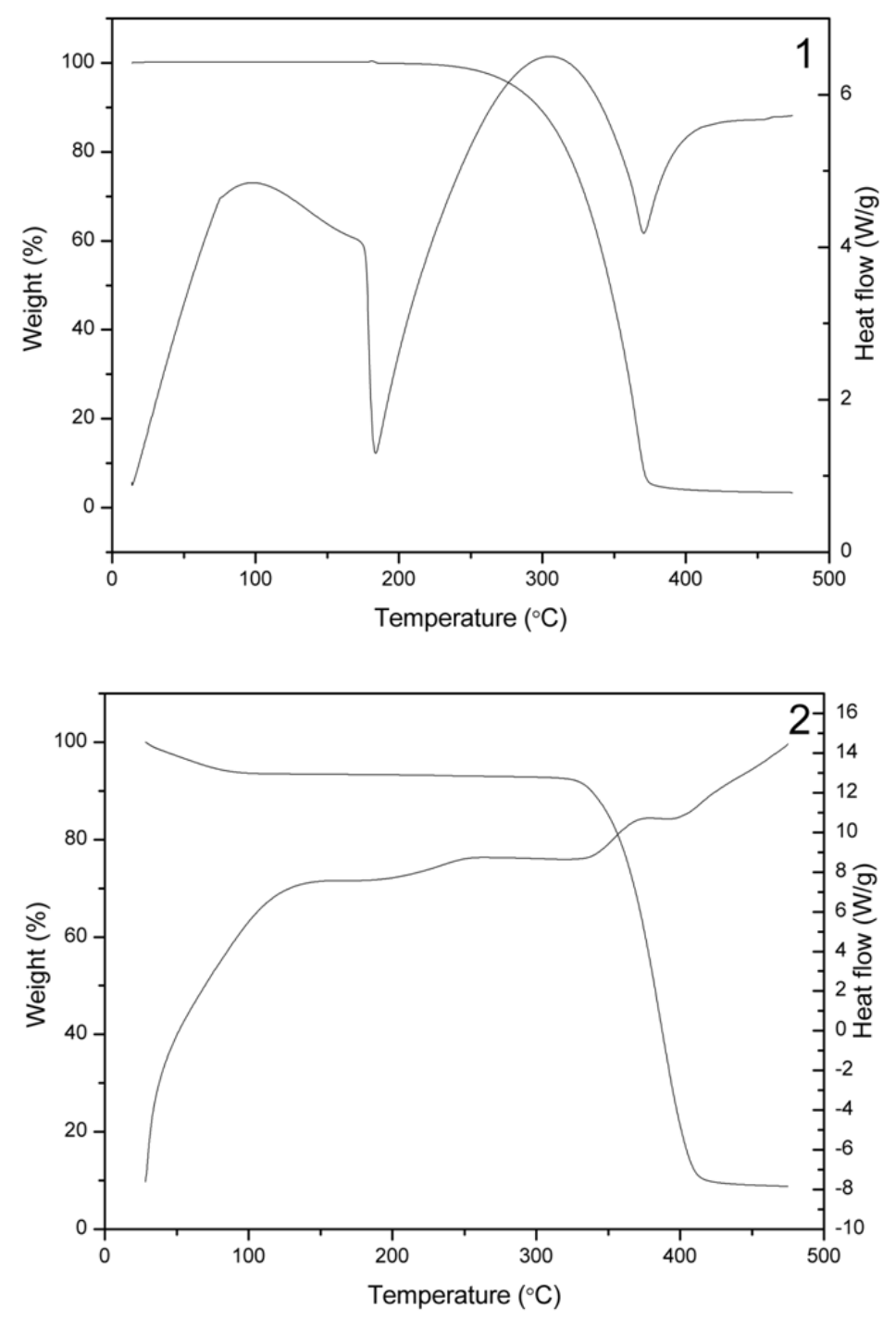

Figure 6: TG/DTA curves of 4'-hydroxylchalcone (1) and its complex (2) 


\section{TG/DSC}

The TG and DSC thermograms of HP- $\beta-C D, 4$ 'hydroxychalcone and their inclusion complex were illustrated in Figure 5-6, respectively. It could be clearly found that the TG and DSC curves of HP- $\beta-C D$ and 4'-hydroxychalcone mainly have one step or one peak, indicating that both the samples were pure compounds. Along with the increase of the temperature, HP- $\beta-C D$ began to decompose at about $320{ }^{\circ} \mathrm{C}$ and this ended at about $420{ }^{\circ} \mathrm{C}$. The decomposing peak value (about $360^{\circ} \mathrm{C}$ ) was obtained from the DSC curve. And the fusion and degradation of HP- $\beta$ $C D$ were completed in one step.

Different from this, the DSC curves of 4'hydroxychalcone had an obvious endothermic peak where the weights of 4'-hydroxychalcone had not decreased, suggesting that 4'hydroxychalcone melted at about $177{ }^{\circ} \mathrm{C}$. Then 4'-hydroxychalcone began degradation at about $200{ }^{\circ} \mathrm{C}$, ending at about $400{ }^{\circ} \mathrm{C}$. At the DSC curve of each complex, there were two endothermic peaks at 344 and $397{ }^{\circ} \mathrm{C}$, respectively. The latter should be the decomposition peak of 4'-hydroxychalcone, with $344{ }^{\circ} \mathrm{C}$ being the peak for HP- $\beta-C D$. Furthermore, the DSC curve showed the disappearance of the melting peak of 4'hydroxychalcone.

\section{DISCUSSION}

Phase solubility study is the quantitative determination of the solubility of a guest substance at the various concentrations of CD, which can yield the solubility diagram of the dissolved guest substance against different concentrations of CD. In this study, the phasesolubility plots of different chalcone-CD complexes all displayed a typical $\mathrm{AL}$ type diagram (i.e., linear increases in chalcone solubility with increasing CD concentrations) within the concentration range studied (Figure 2), indicating 1:1 molecular complexes between the chalcones and CDs [7]. And the stability constants were highest for the complexes formed with HP- $\beta-C D$, followed by $\beta-C D$, which suggested that HP- $\beta-C D$ had the greater capacity to form inclusion complexes with chalcones than the parent $\beta-C D$.

For Table 1, it could be found that the Gibbs energy values were negative for all the complexes, indicating that the inclusion was a spontaneous process and thermodynamically favored. Furthermore, the positive enthalpic and entropic values indicated that the inclusion process was endothermic and mainly entropically driven. The positive entropy together with a slightly positive enthalpic change means that the driving force for the process is essentially hydrophobic interaction [9]. Similar temperature effect on the stability constant was also observed in the complexation of morin with $\beta-C D$ and HP$\beta-C D$ [10]. It was inferred that when the chalcone was free in solution, it may have a strong interaction with its solvent shell. Upon forming an inclusion complex with CDs, this solvent shell was broken up, leading to a partly unfavorable enthalpic change.

According to IR and XRD result, it could be found that that the physical phase of 4'hydroxylchalcone had been changed, which were completely dispersed in HP- $\beta-C D$. For DSC/TG, it could be concluded that the presence of 4'hydroxychalcone in the cavity of HP- $\beta-C D$ made it degrade at a lower temperature. The starting decomposition temperature of 4'hydroxychalcone increased, due to the protection of HP- $\beta-C D$. The decomposition process should be that along with the increase of the temperature, HP- $\beta-C D$ decomposed first and exposed 4'-hydroxychalcone to the heat, 4'hydroxychalcone melted and degraded almost at the same time under so high temperature. A similar result has been reported by [11]. DSC/TG analysis suggested the heat stability of 4'hydroxychalcone could be significantly improved by forming inclusion complex with HP- $\beta-C D$.

\section{CONCLUSION}

Chalcone is a kind of flavonoid with many reported health-promoting properties. However, its low solubility and stability in water impedes its application in pharmaceutical and functional food products. HP- $\beta-C D$ has greater capacity to form inclusion complexes with 4'-hydroxychalcone than the parent $\beta-C D$. Thus, the driving force for the complexation process is hydrophobic interaction. The heat stability of 4'hydroxychalcone is significantly improved by formation of inclusion complex with HP- $\beta-C D$.

\section{ACKNOWLEDGEMENT}

The financial support provided by the Program for Innovative Research Team (in Science and Technology) in University of Henan Province (no. 13IRTSTHN006) is greatly appreciated.

\section{REFERENCES}

1. Wei H, Zhang X, Wu G, Yang X, Pan S, Wang Y, Ruan J. Chalcone derivatives from the fern Cyclosorus

Trop J Pharm Res, December 2014; 13(12): 1976 
parasiticus and their anti-proliferative activity. Food Chem Toxicol 2013; 60: 147-152.

2. Cho S, Kim S, Jin Z, Yang H, Han D, Baek NI, Jo J, Cho CW, Park JH, Shimizu M, Jin YH. Isoliquiritigenin, a chalcone compound, is a positive allosteric modulator of GABAA receptors and shows hypnotic effects. Biochemical and Bioph Res Co 2011; 413: 637-642.

3. Hirai S, Kim YI, Goto T, Kang MS, Yoshimura M, Obata A, Yu R, Kawada T. Inhibitory effect of naringenin chalcone on inflammatory changes in the interaction between adipocytes and macrophages. Life Sci 2007; 81: $1272-1279$

4. Martin Del Valle EM. Cyclodextrins and their uses: a review. Process Biochem 2004; 39: 1033-1046.

5. Astray C, Gonzalez-Barreiro C, Mejuto JC, Rial-Otero R, Simal-Gándara J. A review on the use of cyclodextrins in foods. Food Hydrocolloid 2009; 23: 1631-1640.

6. Szente L, Szejtli J. Highly soluble cyclodextrin derivatives: Chemistry, properties, and trends in development. Adv Drug Deliver Rev 1999; 36: 17-28.
7. Higuchi $T$, Connors $K A$. Phase solubility techniques. Advances in Analytical Chemistry and Instrumentation 1965; 4: 117-212.

8. Rekharsky MV, Inoue Y. Complexation thermodynamics of cyclodextrins. Cheml Rev 1998; 98: 1875-1917.

9. Zhang Q, Jiang Z, Guo Y, Li R. Complexation study of brilliant cresyl blue with $\beta$-cyclodextrin and its derivatives by UV-vis and fluorospectrometry. Spectrochim Acta A 2008; 69: 65-70.

10. Jullian $C$, Orosteguis $T$, Pérez-Cruz $F$, Sánchez $P$, Mendizabal F, Olea-Azar C. Complexation of morin with three kinds of cyclodextrin A thermodynamic and reactivity study. Spectrochim Acta A 2008; 71: 269275.

11. Yuan C, Jin Z, Xu X, Zhuang H, Shen W. Preparation and stability of the inclusion complex of astaxanthin with hydroxypropyl- $\beta$-cyclodextrin. Food Chem 2008; 109: 264-268. 